\title{
The Export Supply Response of Mangoes: A Cointegration and Causality Analysis
}

\author{
Abdul Ghafoor ${ }^{*}$, Khalid Mushtaq ${ }^{* *}$ and Abedullah ${ }^{* * *}$
}

\begin{abstract}
This paper analyzes the impact of major factors on the export of mangoes from Pakistan. We use a cointegration approach and error correction mechanism applied to data for the period 1970-2005. Mango exports are regressed against the index of relative prices of mango exports $(2000=100)$, the quantity of domestic mango production, real agricultural gross domestic product (GDP), the length of all-weather roads, and international standardization, i.e., the impact of the World Trade Organization agreement. The results of the augmented Dickey-Fuller test reveal that all the data series are I(1). Applying Johansen's test shows that the highest elasticity coefficients are found for mango production in the short and long run, followed by real agricultural GDP. The Granger causality test points to the bi-directional causality of mango exports with the relative price index and allweather roads, and unidirectional causality with real agricultural GDP and mango production. The study recommends promoting proper orchard management, developing the appropriate infrastructure, and stabilizing export prices to increase mango exports from Pakistan.
\end{abstract}

Keywords: Mango, unit root, cointegration, Granger causality, Pakistan.

\section{JEL classification: Q11.}

\section{Introduction}

Agriculture is pivotal to Pakistan's economy. Despite the structural shift toward industrialization, agriculture still contributes 21.8 percent to the country's gross domestic product (GDP). It provides a livelihood for about 45 percent of the total employed labor force and contributes significantly to export earnings (Pakistan, Ministry of Finance, 2009). The total value of agriculture at constant factor cost (1999/2000) was estimated

\footnotetext{
* Assistant Professor, Institute of Business Management Sciences, Faculty of Agricultural Economics and Rural Sociology, University of Agriculture, Faisalabad.

** Agricultural Economist, Rural Finance Resource Centre, National Institute of Banking and Finance in Islamabad.

*** Institute of Business Management Sciences, Faculty of Agricultural Economics and Rural Sociology, University of Agriculture, Faisalabad.
} 
at PKR 1,148.871 billion in 2007/08. The major crops (wheat, rice, cotton, and sugarcane) contribute 34 percent, while 11 percent of the agricultural GDP is divided between minor crops. Horticultural crops (fruits, vegetables, and condiments) account for 76 percent of minor crops; fruits, which dominate horticultural crops, account for 59 percent of their total value (Pakistan, Ministry of Food, Agriculture and Livestock, 2008).

Mango exports are an important source of valuable foreign earnings for Pakistan. Exports increased from 1.16 thousand tonnes in 1975/76 to 105.21 thousand tonnes in 2006/07. The last five years have marked a massive increase in mango exports from Pakistan, which is generally attributed to increased access to traditional markets through improved shipping facilities, the rising number of Pakistani immigrants, and government policy ${ }^{1}$ (Pakistan Horticulture Development and Export Board, 2005). Despite the increase in mango exports, however, its share in total mango production remains about 6 percent; this is lower than other leading mango exporters such as Mexico and Brazil, which account for 14 and 12 percent, respectively (Food and Agriculture Organization [FAO], 2007).

Mango exports from Pakistan are highly concentrated in a few markets. The major markets include the United Arab Emirates (UAE) and Saudi Arabia, where expatriate Pakistanis and Indians constitute the major customer base. Increased shipping facilities at cheaper rates, and relatively flexible and less stringent food safety requirements are some of the factors that explain the major share of mango exports to these markets. In 2006/07, 46 percent of the country's mango exports were shipped to the UAE alone, while Saudi Arabia, Oman, Kuwait, and Bahrain accounted for 17.61 percent, 12.79 percent, 1.55 percent, and 1.22 percent, respectively. Almost 76 percent of Pakistani mangoes are exported to three markets (the UAE, Saudi Arabia, and Oman). The UK is Europe's biggest market for total exports from Pakistan, accounting for about 11.46 percent, followed by France (1.48 percent) and Germany (1.22 percent) (Pakistan, Ministry of Food, Agriculture and Livestock, 2007).

Although Pakistan is a leading mango producer (FAO, 2007), it has been unable to reach its full potential as a mango exporter. Arguably, traditional methods of production, improper orchard management, poor post-harvest handling, traditional marketing practices, and lack of compliance with international market requirements have limited the

\footnotetext{
${ }^{1}$ These factors are important determinants of mango exports but were not included in this analysis due to the nonavailability of data. Our study was conducted to evaluate the impact of major factors on mango exports at the macro-level.
} 
country's expansion of mango exports. Mangoes are perishable commodities that require careful handling during the export process. Controlled temperatures, durable packaging, and appropriate transportation are some of the important prerequisites that determine the fruit's freshness and shelf life. Infrastructure development and the availability of reefers (refrigerated transport) further enhance the marketing efficiency required for the export of this delicate fruit.

Other factors that affect mango exports from Pakistan include the relative profitability of selling mangoes in the international market; this is due to the price difference between national and international markets. Exporters often extend their market beyond national borders in the hope of obtaining higher prices for their product abroad. The domestic production of mangoes also influences the export process because it directly affects the exportable surplus. A good mango crop encourages exporters to sell their mangoes abroad whereas a poor crop rarely meets local requirements. The agricultural GDP of any country indicates the size of its market, which signals its attractiveness in the international market, whereas physical infrastructure is essential for exporting commodities, particularly perishables.

Given the importance of mangoes to Pakistan, there is a need to undertake a study that identifies the major determinants of the country's mango exports. This study seeks to identify some of the variables that influence the export of mangoes from Pakistan and to analyze and quantify the impact of the major determinants of the export process in order to devise a strategy to boost mango exports.

\section{A Review of the Literature}

Aujla, Abbas, Mahmood, and Saadullah (2007) investigate the constraints hindering the potential of Pakistan's fruit production and exports. The country's major share in returns from exports comes from the Middle East and Southeast Asia due to the relatively high quantities exported to these regions. Pakistan's inability to compete in the world's more expensive markets for horticultural products is explained by the nonavailability of infrastructure, the mismatch of Pakistan's fruits with the tastes and preferences of high-price markets, the high cost of refrigerated transport facilities and good-quality packing material, the lack of other inputs needed in processing, and credit constraints. These are important variables but are difficult to include in a quantitative analysis due to the 
nonavailability of specific data. Infrastructure, however, can be included by using a proxy variable such as the length of roads available.

Haleem (2005) investigates the export supply response of mangoes in Pakistan during 1975-2004, using Johansen's cointegration technique. The estimated export price elasticity for mangoes was 5.39, the domestic price elasticity was -6.73 , and the domestic production elasticity was -2.16 . The exchange rate elasticity remained 2.89. Although the study makes a sound attempt to evaluate the major determinants of mango exports from Pakistan at the macro-level, we prefer to use the relative price index instead of using domestic and export prices separately as independent variables. Haleem also finds the elasticity of mango production to be a little higher than in our study.

Haleem, Mushtaq, Abbas, and Sheikh (2005) examine the factors affecting citrus exports. These include domestic and export prices, national production, and foreign exchange rates. They use time-series data for the period 1975-2004, and employ cointegration and an error correction mechanism (ECM). The estimated export price elasticity is 1.48 while domestic price elasticity is -0.98 . Among nonprice factors, the estimated elasticity of domestic citrus production, the exchange rate, and GDP are $1.37,1.31$, and 0.35 , respectively.

Hassan and Ibnouf (2005) identify competitive capacity determinants (relative prices, relative stability of production, and efficiency of export practices) for Egyptian exports of certain fruits to the Saudi Arabian market, using time-series data for the period 1985-2000. They estimate multiple linear regression equations And their results indicate that the competitive capacity of Egyptian exports for these major fruits in the Saudi Arabian market could be increased by expanding the production of quality oranges and lemons, improving the efficiency of export processes, and reducing the cost of mango production while meeting product specifications and maintaining the relative stability of production. Although the study is country-specific, it helps to identify two major variables of the export model: the relative price index and the production status of the fruit in question.

Using time-series data for the period 1975-2003, Neef (2004) studies the export patterns for pears, apples, and strawberries from Belgium. The study finds that internal factors such as production and per capita availability play an important role in explaining variations in net exports, while external factors such as prices and foreign exchange rates 
appear to be less important. Tambi (1999) discusses factors that influence Cameroon's exports of cocoa, coffee, and cotton, applying a cointegration analysis. The combined short-run dynamic effect of lagged quantities of cocoa and coffee, the export/domestic price ratio, and GDP jointly explain changes in the export of cocoa, while lagged quantities of cocoa, coffee, and cotton do not seem to have significant short-run dynamic effects on changes in coffee exports.

Gunawardana, Kidane, and Kulendran (1995) estimate the export supply response of the Australian citrus industry using cointegration and error correction techniques. Their results show that, even in the long run, the supply of citrus exports is inelastic with respect to relative prices while domestic production capacity has a positive impact on export supply. The long-run price elasticity is found to be 0.73 . Our findings are similar in that the relative price of mangoes has an inelastic impact on exports, while production capacity has a positive impact.

Reddy and Narayan (1992) assess the trade experience of Indian agriculture and the behavior of the net export supply functions for dominant commodities, i.e., rice, wheat, cotton, tobacco, sugar, jute, and tea, using autoregressive distributed lag formulations. They find that internal factors such as production and per capita availability play an important role in explaining variations in net exports, while external factors such as prices and foreign exchange rates are less important.

Islam (1990) identifies various factors affecting horticultural exports from developing countries, including GDP, the exchange rate, production, and social and physical infrastructure, and calculates the effect of these variables by estimating regressions in logarithmic form. In the first model, production, GDP, the real exchange rate, and the index of trade dependence are found to significantly affect exports. In the second model, GDP is replaced by two variables representing physical and human infrastructure, both of which are found to be significant. The share of manufacturing exports in total exports is also found to have a significant positive effect. The study calculates the price and income elasticities for the demand and supply of horticultural exports: -0.71, 0.74, and 1.08, respectively. It also helps to identify an important variable, i.e., GDP, which can be used to capture the effect of market size.

The literature review highlights two important points. First, it supports the use of cointegration to analyze time-series data; second, it helps to identify the major variables determining the export of perishable 
commodities at the macro-level. As mentioned earlier, this study was conducted to evaluate the impact of major variables (domestic production, GDP, infrastructure, and the relative price index) on mango exports from Pakistan using cointegration and ECM techniques.

\section{Conceptual and Empirical Framework}

We estimate the export supply response of mangoes using cointegration and ECM techniques applied to secondary data for the period 1970-2005,2 collected from various sources including the FAO database, and various issues of the Pakistan Economic Survey and Pakistan Statistical Year Book. Johansen's approach is used to test for cointegration between mango exports and its explanatory variables, and the ECM is used to estimate short- and long-run elasticities. The Granger causality test is conducted to determine the direction of causation between variables to draw policy conclusions.

\subsection{Empirical Model}

The specific form of the mango export supply function is:

$$
\ln E x_{t}=\gamma_{0}+\gamma_{1} \ln R P_{t}+\gamma_{2} \ln P_{t}+\gamma_{3} \ln G_{t}+\gamma_{4} \ln R D_{t}+\gamma_{5} D S_{t}+\mu_{t}(1)
$$

$E x_{t}$ represents mango exports (in thousand tonnes), $R p_{t}$ is the index of relative prices of mango exports $(1999 / 2000=100), P_{t}$ represents domestic mango production (in thousand tonnes), $G_{t}$ is real agricultural GDP measured at a constant factor cost of 1999-2000 (in million rupees), $R d_{t}$ represents the length of all-weather roads (in thousand kilometers) as a proxy variable for infrastructure, $D S$ is a dummy variable used to capture the effect of international standardization, and $\mu_{t}$ is a stochastic error term.

\subsection{Data Sources and Variable Specification}

The sources of data, the rationale for choosing specific variables, and their construction are discussed below.

\footnotetext{
${ }^{2}$ The data was collected from the FAO database, which provides data on mango exports and value till 2005 beyond which the data on mangoes is combined with that on guavas and mangosteen.
} 


\subsubsection{Mango Exports}

This variable is taken as a dependent variable and regressed against domestic mango production, the index of relative prices, real agricultural GDP, the length of all-weather roads, and international standardization. For this purpose, data on mango exports was taken from the FAO's (2007) database and measured in thousand tonnes.

\subsubsection{Mango Production}

The level of domestic production is considered important because it determines the volume available for export purposes. This is particularly important for developing countries where exportable surplus is generated after local requirements have been met. A good crop harvest will increase the probability of exporting more of that commodity. The domestic production of mangoes was identified as one of the major determinants of exports from Pakistan. Data on this variable was obtained from the FAO's (2007) database and measured in thousand tonnes.

\subsubsection{Index of Relative Prices}

The index of relative prices of mango exports is calculated as follows, using 1999/2000 as the base year:

$$
R P_{1}=\frac{P X I N}{P D I N} \times 100
$$

where $R P$ is the index of relative prices of mango exports, PXIN is the index of the Pakistani rupee price of mango exports, and PDIN is the index of the domestic wholesale price of mangoes.

This variable indicates the relative profitability of selling in export markets over that of selling in domestic markets. The index of national prices of mangoes is constructed using 1999/2000 as the base year. The index of export prices is calculated in the same way.

The data for this purpose was taken from the FAO's (2007) database. Data on domestic wholesale prices was taken from various issues of the Pakistan Bureau of Statistics' Pakistan Statistical Year Book. These prices were then used to construct a national average price for mangoes. Data on the export value of mangoes was obtained from the FAO's (2007) database in thousand dollars per tonne. The export prices of mangoes were 
calculated by dividing their export value by the export quantity for each year and converted into thousands of rupees at the official exchange rate.

\subsubsection{Real Agricultural GDP}

A country's agricultural GDP indicates the size of its market and level of economic growth in the agriculture sector. A country with a high agricultural GDP may be a good performer, making it an active exporter in the international market. For the purposes of this study, we calculated the agricultural GDP at constant factor cost (in PKR million) for each year, and divided it by the GDP deflator for that year to convert each value into real terms. Data on agricultural GDP and the GDP deflator was obtained from the State Bank's Economic Bulletins.

\subsubsection{Infrastructure Development (All-Weather Roads)}

Governments invest in developing infrastructure because it affects both the quality and quantity of agricultural produce by enhancing the link between production and consumption. In empirical research, determining an accurate and exact variable, such as infrastructure development, can be difficult. Although we considered the use of variables such as storage capacity, processing units, and the quantity of mangoes transported from farms to processing factories to capture the effect of infrastructure development, data for these variables was not available. Accordingly, we have used a proxy variable to capture the effect of infrastructure development on mango exports, i.e., the length of all-weather (metalled) roads. Data on all-weather roads (in kilometres) was taken from various issues of the Pakistan Economic Survey.

\subsubsection{International Standardization (Dummy Variable)}

A dummy variable was used to capture the effect of international standardization-i.e., the implementation of World Trade Organization (WTO) agreements - on the export of mangoes from Pakistan. The variable was constructed by assigning a value of 0 to years prior to the implementation of WTO agreements and 1 to years thereafter.

\subsection{Johansen's Cointegration Approach}

In dealing with secondary data, classical regression analysis assumes that time-series data is stationary, but that most time series trend over time, which, if regressed, may be spurious (Granger \& Newbold, 1974). Time-series data is said to be stationary if its mean, variance, and 
covariance are constant over time (Gujarati, 1995). Thus, before undertaking our analysis, we test the data series for the presence of any unit roots, i.e., for nonstationarity using the augmented Dickey-Fuller (ADF) test as follows:

$$
\Delta Y_{t}=\alpha_{3}+\beta_{3}\left(\phi_{3}-1\right) Y_{t-1}+\sum_{i=1}^{k} \theta_{i} \Delta Y_{t-i}+\mu_{t}
$$

where $Y_{t}$ is the series under consideration and $\mu_{t}$ is assumed to be an identically and independently distributed random variable. The ADF test determines statistically the null hypothesis that the time series of the given variables has a unit root against the alternative hypothesis of a stationary time series (Dickey \& Fuller, 1981).

The concept of cointegration was introduced by Granger (1981, 1983) and statistically analyzed by Engle and Granger (1987). In the literature, there are two major approaches to testing for cointegration: the residuals-based ADF approach proposed by Engle and Granger (1987) and Johansen's full information maximum likelihood approach (Johansen, 1988; Johansen \& Juselius, 1990). The Engle and Granger approach entails testing for cointegration and then using residuals in an ECM to obtain information on the speed of adjustment in the long run. The major weaknesses of this approach, however, include its low power and finite sample bias. It cannot be used in a situation where there are more than two variables (Dolado, Jenkinson, \& Sosvilla-Rivero, 1991; Charemza \& Deadman, 1992), making Johansen's approach preferable. The following vector autoregressive (VAR) model forms the basis of the multivariate cointegration of Johansen's maximum likelihood approach (Johansen \& Juselius, 1990):

$$
Z_{t}=A_{i} Z_{t-1}+\ldots \ldots+A_{k} Z_{t-k}+\mu_{t}
$$

where $Z_{t}$ is an $(n \times 1)$ vector of $I(1)$ variables with both endogenous and exogenous variables, $A_{i}$ is an $(n \times n)$ matrix of parameters, and $\mu_{t}$ is an $(n \times$ 1) vector of white noise errors. Each equation in (3) can be estimated using ordinary least squares (OLS) because each variable in $Z_{t}$ is regressed on lagged values of its own and all other variables in the system. Since $Z_{t}$ is assumed to be nonstationary, it is convenient to rewrite equation (3) in its first difference or error correction form (Cuthbertson, Hall, \& Taylor, 1992) as

$$
\Delta Z_{t}=\Gamma_{i} \Delta Z_{t-1}+\ldots \ldots . .+\Gamma_{k-1} \Delta Z_{t-k+1}+\Pi Z_{t-k}+\mu_{t}
$$


where

$$
\begin{aligned}
& \Gamma_{i}=-\left(I-A_{1}-A_{2}-\ldots . . A_{i}\right),(i=1, \ldots \ldots ., k-1), \text { and } \\
& \Pi=-\left(I-A_{1}-A_{2}-, \ldots . .,-A_{k}\right)
\end{aligned}
$$

The specification above provides information on the short-run and long-run adjustments to the changes in $Z_{t}$ by estimating $\Gamma$ and $\Pi$, respectively. The term $\Pi Z_{t-k}$ gives information on the long-run equilibrium relationship between the variables, while information about the number of cointegrating relationships among the variables in $Z_{t}$ is given by the rank of the matrix $\Pi$. If the rank of the matrix $\Pi$ is $0<r<n$, there are $r$ linear combinations of the variables in $Z_{t}$ that are stationary.

Here, the $\Pi$ matrix can be decomposed into two matrices, $\alpha$ and $\beta$, such that $\Pi=\alpha \beta$, where $\alpha$ is the error correction term measuring the speed of adjustment in $\Delta Z_{t}$, and $\beta$ contains $r$ distinct cointegrating vectors, i.e., the cointegrating relationship between the nonstationary variables. The model may have some variables that are $I(0)$ and are insignificant in the long-run cointegrating space but that affect the short-run model. In this case, equation (4) can be written as:

$$
\Delta Z_{t}=\Gamma_{i} \Delta Z_{t-1}+\Pi Z_{t-k}+\psi D_{t}+\mu_{t}
$$

where $D_{t}$ represents the $I(0)$ variable, which is often included to take account of short-run shocks to the system, such as policy interventions.

Johansen and Juselius (1990) use two likelihood ratio tests-trace and maximum eigenvalue tests-to determine the cointegration rank and estimate the long-run parameter matrix. The trace test is based on the stochastic matrix and is defined as:

$$
\lambda_{\text {trace }}=-2 \ln Q=-T \sum_{i=r+1}^{p} \ln \left(1-\lambda_{i}\right)
$$

The null hypothesis of this test is that the number of distinct cointegrating vectors is less than or equal to $r$ (i.e., no cointegrating vector) against the alternative that $r>0$ (i.e., one or more cointegrating vectors). The maximum eigenvalue test, used to detect the presence of a single cointegrating vector, is based on the following:

$$
\lambda_{\max }=-2 \ln (Q: r \mid r+1)=-T \ln \left(1-\lambda_{r+1}\right)
$$


This statistic tests the null hypothesis that the number of cointegrating vectors is $r$, against the specific alternative of $(r+1)$ cointegrating vectors. The distribution of these statistics depends on the number of nonstationary components (i.e., the number of variables we are testing for cointegration) defined by $(n-r)$. The Monte Carlo derivation of critical values for these tests has been simulated and tabulated by Johansen (1988) and Osterwald-Lenum (1992). Harris (1995) considers the trace test to be more powerful.

The Granger representation theorem states that, if a set of variables is cointegrated, this implies that the residual of the cointegrating regression is of order I(0); thus, there exists an ECM describing this relationship. The theorem explains that cointegration and an ECM can be used as a unified theoretical and empirical framework to analyze both short- and long-run behavior. If the series $Y_{t}$ and $X_{i t}$ are $I(1)$ and cointegrated, then the ECM is represented in the following form:

$$
\begin{aligned}
& \Delta X_{i t}=\alpha_{0}+\sum_{t=1}^{n} \beta_{i} \Delta X_{(t-1), i}+\sum_{t=1}^{n} \beta_{j} \Delta X_{(t-1), j}+\delta E C T_{t-1}+\mu_{t} \\
& \Delta X_{j t}=\varphi_{0}+\sum_{t=1}^{n} \sigma_{j} X P_{(t-1), j}+\sum_{t=1}^{n} \sigma_{i} X_{(t-1), i}+\lambda E C T_{t-1}+\varepsilon_{t}
\end{aligned}
$$

where $\Delta$ is the difference operator, $X_{i t}$ is the mango export series $(i=1)$, and $X_{j t}$ represent the independent variables mentioned earlier $(i=2 \ldots 5)$. $\mu_{t}$ and $\varepsilon_{t}$ are white noise error terms, $E C T_{t-1}$ is the error correction term (adjustment vector) derived from the long-run cointegrating relationship, and $n$ represents the optimal lag length orders of the variables that are determined using the general-to-specific modeling procedure (Hendry \& Ericsson, 1991). The null hypotheses are: $X_{i t}$ will Granger-cause $X_{j t}$ if $\mu_{t} \neq 0$. Similarly, $X_{j t}$ will Granger-cause $X_{i t}$ if $\varepsilon_{t} \neq 0$. To apply the Granger causality test, we calculate the F-statistics under the null hypothesis that, in the above equations, all the coefficients of $\mu_{t}$ and $\varepsilon_{t}$ are equal to 0 .

\section{Results and Discussion}

The analysis was conducted in three steps. First, the ADF test was used to test for the presence of unit roots in the variables. Next, Johansen's full information maximum likelihood approach was used to test the longrun relationship between variables and an ECM was employed to obtain 
short-run elasticities. Finally, the direction of causation between variables was tested using the Granger causality test.

\subsection{Test for Stationarity (Unit Root Test)}

The null of the unit root is tested against the alternative hypothesis of stationarity by the ADF regressions, first by including an intercept but not a trend, and then by including both an intercept and a linear trend. The maximized log-likelihood, Akaike information criterion (AIC), and Schwarz Bayesian criterion (SBC) are used to determine the optimal lag length of the augmented terms. The computed absolute value of the test statistic (Dickey-Fuller statistic) is checked against the maximum values of these criteria applying a 95 percent absolute critical value for the ADF statistic. If the computed absolute test statistic value is greater than the absolute critical value, we can reject the null of the unit root, which implies that the time series is stationary. On the other hand, if the absolute test statistic value is less than the absolute critical value, then we accept the null of the unit root, implying that the series is nonstationary.

The variable of mango exports (LEx) is tested for the presence of a unit root using the ADF test. The computed absolute value for the nontrended model is -0.73 , which is far smaller than the 95 percent absolute critical value for the ADF statistic. The computed absolute value for the trended model is -2.38 , which again falls below the 95 percent absolute critical value for the ADF statistic. Both these tests confirm that the data series on mango exports is nonstationary. The other variables are also tested for the presence of a unit root and found to be nonstationary (Table 1).

Table 1: Results of unit root test

\begin{tabular}{lccc}
\hline Variable & Nontrended model & Trended model & $\varphi_{3}$ \\
\hline LEx & -0.73 & -2.38 & 5.80 \\
LRp & -2.81 & -2.78 & 6.16 \\
LP & -0.29 & -3.37 & 2.86 \\
LG & -0.25 & -2.64 & 4.47 \\
LRd & -1.97 & -0.53 & 0.46 \\
Critical value & -2.93 & -3.50 & 6.73 \\
\hline
\end{tabular}

Source: Authors' calculations. 
The next step is to confirm our results by checking for the presence of a unit root in the first difference of these data series. All the data series are found to be $I(1)$ (Table 2).

Table 2: Results of unit root test for first-difference series

\begin{tabular}{lcc}
\hline Variable & Nontrended model & Trended model \\
\hline LEx & -5.50 & -5.42 \\
LRp & -5.85 & -5.73 \\
LP & -4.50 & -4.48 \\
LG & -6.30 & -6.19 \\
LRd & -3.96 & -3.67 \\
Critical value & -2.97 & -3.58 \\
\hline
\end{tabular}

Source: Authors' calculations.

\subsection{Testing for Cointegration}

After testing for unit roots in the given data series, we estimate the cointegrating regression between the variables to determine their long-run relationship. In the first stage, we identify the order of the VAR model using the adjusted likelihood ratio (LR) test and the AIC and SBC with a maximum of four lags. The results for the selection of the order of the VAR model identifies order 1 against the SBC's largest value. The AIC does not support this result; its largest value suggests the order of 3 for the VAR model. However, the final selection is made on the basis of the adjusted LR test, which confirms the SBC's suggested order since the adjusted LR test value became insignificant for the first time at the order of 1 . Thus, the selected order of the VAR model for our mango export supply response model is estimated to be 1 (Table 3).

Table 3: Selecting the order of the VAR model

\begin{tabular}{lccc}
\hline Order & AIC & SBC & Adjusted LR test \\
\hline 3 & 181.04 & 103.60 & - \\
2 & 163.79 & 112.17 & $47.06(0.10)$ \\
1 & 167.80 & 141.99 & $85.56(0.94)$ \\
0 & 130.88 & 130.88 & $236.71(0.00)$ \\
\hline
\end{tabular}

Note: $\mathrm{AIC}=$ Akaike information criterion, $\mathrm{LR}=$ likelihood ratio, $\mathrm{SBC}=$ Schwarz Bayesian criterion. Values in parentheses are p-values.

Source: Authors' calculations. 
We then test for the presence and number of cointegrating vectors in the model's series. The rank of cointegration, i.e., the number of cointegrating vectors, is selected using maximum eigenvalues and trace value test statistics. For this purpose, there are three possible models ${ }^{3}$ but based on a set of model fitness criteria, we select and explain the second model. Based on the maximum eigenvalue test statistics, the hypothesis of no cointegration is rejected and the alternative hypothesis of the existence of cointegration in the series is accepted: the results of the maximum eigenvalues test show that values are significant at 5 percent for the first test statistics because the first statistical value for the test is greater than the 95 percent critical value. According to Harris (1995), the number of cointegrating vectors is one when the null hypothesis is rejected for the first time. Thus, on the basis of these results, we can safely assume that there is one cointegrating vector in the series (Table 4).

Table 4: Cointegrating LR test based on maximum eigenvalues of stochastic matrix

\begin{tabular}{lcccc}
\hline $\mathbf{H}_{\mathbf{o}}$ & $\mathbf{H}_{\mathbf{A}}$ & Model 2 & Model 3 & Model 4 \\
\hline $\mathrm{R}=0$ & $r=1$ & $69.61(40.53)$ & $47.26(39.83)$ & $52.92(43.61)$ \\
$\mathrm{R} \leq 1$ & $r=2$ & $27.30(34.40)$ & $18.05(33.64)$ & $25.82(37.86)$ \\
\hline
\end{tabular}

Note: $r$ is the number of cointegrating vectors; 95 percent critical values are given in parentheses.

Source: Authors' calculations.

The results of the trace test confirm the results obtained using maximum eigenvalues, yielding one cointegrating vector because the test shows that the values are significant at 5 percent for the first test statistics since the first statistic value for the tests is greater than the 95 percent critical value. Thus, in the case of both tests, we reject the possibility of two cointegrating vectors and assume one cointegrating vector in the series (Table 5).

\footnotetext{
3 Model 2: Cointegration with restricted intercepts and no trends in the VAR. Model 3: Cointegration with unrestricted intercepts and no trends in the VAR. Model 4: Cointegration with unrestricted intercepts and restricted trends in the VAR.
} 
Table 5: Cointegrating LR test based on trace values of stochastic matrix

\begin{tabular}{lrrrr}
\hline $\mathbf{H}_{\mathbf{o}}$ & $\mathbf{H}_{\mathbf{A}}$ & \multicolumn{1}{c}{ Model 2 } & \multicolumn{1}{c}{ Model 3 } & \multicolumn{1}{c}{ Model 4 } \\
\hline $\mathrm{R}=0$ & $r \geq 1$ & $148.87(102.56)$ & $95.96(95.87)$ & $116.18(115.82)$ \\
$\mathrm{R} \leq 1$ & $r \geq 2$ & $69.25(75.98)$ & $48.00(70.49)$ & $61.26(87.17)$ \\
\hline
\end{tabular}

Note: $r$ is the number of cointegrating vectors; 95 percent critical values are given in parentheses.

Source: Authors' calculations.

\subsection{Johansen's Normalized Estimates and ECM Estimates}

In our estimation of an ECM for mango exports, we include the same number of lags as for the unit root and cointegration tests, i.e., four lags. The parameters of the Johansen cointegration regression are the estimates of the long-run elasticities whereas the coefficients of the difference terms in the ECM are the estimates of the short-run elasticities.

The relative price index variable shows the relative profitability of selling mangoes in export markets compared to local markets. This variable is significant both in the short and long run-their t-values are 3.43 and 2.50 , respectively (Table 6). This shows that the variable is significant at a 1 percent and 5 percent level of confidence, respectively. The variable's direction in the short run as well as in the long run is also consistent-it has a positive sign relative to mango exports, which implies that relative price rises in the export market increase mango exports from Pakistan because this increases the relative profitability linked with the price increase.

The variable's elasticity coefficient in the short run indicates that a one-percent increase in the relative price index leads to a 0.36 percent increase in mango exports from Pakistan. The elasticity coefficient increases up to 0.55 in the long run, which implies that a one-percent increase in the relative price index introduces a 0.55 percent increase in mango exports. A larger long-run elasticity coefficient for mango exports with respect to the relative price index is logical because mango crops require an additional year to respond to any price changes; in the case of a quantum response by domestic mango production to rising international prices, it may be necessary to grow an entirely new crop, which could take several years. So, mango exports are more responsive to the relative price index in the long run than the short run.

The mango production variable provides a base for developing a strong export culture for mangoes in Pakistan. The t-values for mango 
production in the short and long run are 2.64 and 1.58, respectively, which show that the variable is significant at a 5 percent level of confidence in the short run and at a 10 percent level of confidence in the long run (Table 6). The variable's direction in the short and long run is also consistent because it has a positive sign in relation to mango exports. This implies that an increase in mango production enhances the level of mango exports from Pakistan.

The variable's elasticity coefficient in the short run indicates that a one-percent increase in mango production leads to a 2.87 percent increase in mango exports from Pakistan. The elasticity coefficient falls to 1.43 in the long run, implying that a one-percent increase in mango production introduces a 1.43 percent increase in mango exports. The smaller elasticity coefficient in the long run indicates an absence of export planning for mangoes. It is also clear that Pakistan has not capitalized on its potential for increasing exports over time.

The real agricultural GDP variable indicates the pace of relative economic growth and market size in Pakistan. The variable is significant both in the short and long run-their t-values are both 1.83 (Table 6). This shows that the variable is significant at a 10 percent level of confidence both in the short and long run. The variable's direction in the short and long run is also consistent since it has a positive sign in relation to mango exports, implying that growth in real agricultural GDP increases mango exports from Pakistan. As mentioned in Section 3, agricultural GDP indicates the relative size of the economy as well as its stage of development. A well-developed economy, denoted by the value of its agricultural GDP, will be suited to exporting agricultural commodities.

Pakistan, an agriculture-based economy, is a case in point. The elasticity coefficient for this variable in the short run indicates that a onepercent increase in real agricultural GDP leads to a 0.97 percent increase in mango exports from Pakistan. The elasticity coefficient rises to 1.03 in the long run, implying that a one-percent increase in real agricultural GDP introduces a 1.03 percent increase in mango exports. So, mango exports are more responsive to real agricultural GDP in the long run than in the short run.

The impact of infrastructure development on mango exports is assessed using the length of all-weather roads as a proxy variable. In Pakistan, the road network can be divided into two categories, i.e., allweather roads, which are metalled links between urban and rural areas, 
and low-type roads, which are not useable in the rainy season. This variable is insignificant in the short run and significant at a 10 percent level of confidence in the long run-the t-values for the short run and long run are 0.40 and 1.93 , respectively (Table 6).

The variable's direction both in the short and long run is also consistent; it has a positive sign in relation to mango exports, which implies that an increase in the length of all-weather roads increases mango exports from Pakistan. The variable's elasticity coefficient in the short run indicates that a one-percent increase in the length of all-weather roads leads to a 0.55 percent increase in mango exports; the elasticity coefficient rises to 0.56 in the long run, implying that a one-percent increase in the length of allweather roads introduces a 0.56 percent increase in mango exports. So, mango exports are slightly more responsive to infrastructure development in the long run than in the short run.

A dummy variable is used to determine the impact of international standardization, i.e., WTO agreements. This variable is insignificant in the long run but significant at a 10 percent level of confidence in the short run.

The coefficient of the error correction term has a negative sign, which corresponds to theory and explains the adjustment process and speed of adjustment from any short-run shock toward long-run equilibrium. The error correction term is -0.52, which is highly significant, suggesting that 52 percent of any disequilibrium in the short run will adjust in the unit time period (one year in this case). This means that any short-run adjustment will be fully compensated for in almost less than two years. 
Table 6: Estimated long- and short-run elasticities

\begin{tabular}{lcccc}
\hline \multirow{2}{*}{ Regressor } & \multicolumn{2}{c}{ Short run } & \multicolumn{2}{c}{ Long run } \\
\cline { 2 - 5 } Constant & Elasticity & t-value & Elasticity & t-value \\
LRp & 0.29 & $2.03^{* *}$ & 25.70 & 1.13 \\
LP & 0.36 & $3.43^{* * *}$ & 0.55 & $2.50^{* *}$ \\
LG & 2.87 & $2.64^{* *}$ & 1.43 & $1.58^{*}$ \\
LRd & 0.97 & $1.83^{*}$ & 1.03 & $1.83^{*}$ \\
DS & 0.55 & 0.40 & 0.56 & $1.93^{*}$ \\
Ecm1(-1) & 0.17 & $1.96^{*}$ & 0.55 & 1.34 \\
Diagnostic tests & -0.528 & $-4.28^{* * *}$ & & \\
$\mathrm{R}^{2}$ & 0.67 & & \\
DW statistics & 1.92 & Jarque-Bera normality- $\aleph^{2}$ & 0.614 \\
LM- $\chi^{2}$ & $3.44(0.20)$ & Wald test- $\aleph^{2}$ & & 0.159 \\
\hline
\end{tabular}

Note: ${ }^{* * *}=$ significant at 1 percent level, ${ }^{* *}=$ significant at 5 percent level, ${ }^{*}=$ significant at 10 percent level.

Source: Authors' calculations.

All the diagnostic tests conducted in this analysis yield satisfactory results, which confirm the authenticity of the estimation process and estimates. The Lagrange multiplier (LM) test indicates that there is no problem of serial correlation among the residuals since the computed value is greater than 0.05 and we can reject the null of serial correlation among the residuals. The Ramsey regression equation specification error test (RESET) also verifies the correct functional form of the model. The JarqueBera test confirms the normal distribution of the residuals. The Wald test provides the significance level supporting the ECM over the partial adjustment specification. The $\mathrm{R}^{2}$ value indicates that about 67 percent of the variation in mango exports is explained by the independent factors included in the model. The Durban-Watson statistics also verify that there is no serial correlation among the residuals (Table 6).

\subsection{Granger Causality Test}

Granger causality assumes that information relevant to the prediction of the variables in question is contained solely in the time-series data. Here, causality refers to the direction of cause from one variable to the other, which is regressed separately on each other (Gujarati, 1995). Once we have determined the short- and long-run relationships between the variables, it is also useful to determine the direction of cause between them. 
We run separate regressions for each of the explanatory variables, which are of $I(1)$ with the dependent variable mango exports, including an error correction term, and determine the Granger causality. First, we regress mango exports (LEx) and real agricultural GDP (LG) separately on each other. The results suggest unidirectional causality from real agricultural GDP (LG) to mango exports (LEx) since the estimated Fstatistic (6.01) and respective P-values are significant (Table 7). There is no reverse causation from mango exports (LEx) to real agricultural GDP (LG) since the computed F-statistic (0.85) is not statistically significant. The agricultural GDP of a country shows its growth pattern and market size, so it seems logical that real agricultural GDP should affect mango exports. However, the share of mango exports in agricultural GDP is not large enough to lead to a causative change from mango exports (LEx) to real agricultural GDP (LG).

Next, the causative relationship between mango exports (LEx) and the relative price index (LRp) is determined by regressing each separately on the other. The results suggest bi-directional or bilateral causality between the two variables. In the first case, the estimated F-statistic (6.04) and P-value are significant, implying that the relative price index (LRp) Granger-causes a change in mango exports (LEx). Similarly, there is reverse causation from mango exports (LEx) to the relative price index (LRp) since the F-statistic (12.83) is again statistically significant (Table 7). The relative price index (LRp) shows the relative profitability of selling mangoes in the local market as against the international market, so as a policy implication, this variable should cause a change in mango exports. Conversely, mango exports might not be independent of the relative price index because price is one of its most important determinants.

In determining the causative relationship between mango exports (LEx) and mango production (LP), the results suggest unidirectional causality from mango production (LP) to mango exports (LEx) since both the estimated F-statistic (4.64) and respective P-values are significant. There is no reverse causation from mango exports (LEx) to mango production (LP) since the computed F-statistic (0.78) is not statistically significant (Table 7). Mango production is the basis for exports, and so it Grangercauses mango exports, but this is not applicable in reverse because mango exports constitute a small proportion of the total mango production in Pakistan and there is apparently no difficulty in obtaining an exportable surplus for export. There is, therefore, only unidirectional causation between these two variables. 
Finally, we determine the causative relationship between mango exports (LEx) and all-weather roads (LRd) (the proxy variable for physical infrastructure) by regressing both separately on each other. The results suggest bi-directional or bilateral causality since both the estimated Fstatistic (4.55) and respective P-values are significant (Table 7). This implies that all-weather roads (LRd) Granger-cause a change in mango exports (LEx). Similarly, there is reverse causation from mango exports (LEx) to allweather roads (LRd) since the computed F-statistic (3.49) is again statistically significant. Physical infrastructure is one of the basic requirements of enhancing the quality of the domestic marketable surplus, which further acts as a primary source for generating exportable commodities. Bi-directional causality between these two variables is, therefore, a logical outcome.

Table 7: Results of Granger causality test from ECM

\begin{tabular}{lccc}
\hline Causality & F-statistics & P-value & Direction \\
\hline LG $\rightarrow$ LEx & 6.01 & $0.003^{*}$ & Unidirectional \\
LEx $\rightarrow$ LG & 0.85 & 0.47 & \\
LR $\rightarrow$ LEx & 6.04 & $0.003^{*}$ & Bi directional \\
LEx $\rightarrow$ LRp & 12.83 & $0.01^{*}$ & \\
LP $\rightarrow$ LEx & 4.64 & $0.01^{*}$ & Unidirectional \\
LEx $\rightarrow$ LP & 0.78 & 0.51 & \\
LRd $\rightarrow$ LEx & 4.55 & $0.01^{*}$ & Bi directional \\
LEx $\rightarrow$ LRd & 3.49 & $0.03^{*}$ & \\
\hline
\end{tabular}

* Significant.

Source: Authors' calculations.

\section{Recommendations}

Our findings show that the highest elasticity coefficient in the short and long run is found for mango production followed by real agricultural GDP. In this context, improving the production potential of mangoes would be a good initiative to enhance their export from Pakistan. Mango growers should be trained in the scientific management of their orchards. Policies conducive to boosting agricultural GDP are also advisable, in which connection investment in agriculture, particularly to add value to the exportable surplus, would be a good policy direction to take.

Infrastructure is a prerequisite for boosting exports by developing a link between production areas and terminal markets. Mangoes are locally 
transported in trucks since refrigerated reefers are limited. The road network in Pakistan has improved but many roads are still not in good condition. There should be greater investment in the provision of refrigerated reefers; at the same time, a network of motorways should be established across Pakistan linking production and terminal markets. Our findings, in which road length has been used as a proxy variable for infrastructure, show that it significantly affects mango exports both in the short and long run.

Another important finding is the significant and positive impact of sale price on mango exports. Currently, mangoes from Pakistan are considered a low-price product in various export markets. Most exporters target traditional low-value markets. Another important requirement for exporting mangoes from Pakistan on a sustainable basis is compliance with international standardization such as WTO agreements. In this context, we recommend adopting an integrated, uniform effort (through the mutual cooperation of the private and public sectors). In addition, greater marketing efforts are needed to develop a better image of Pakistani mangoes by arranging seminars, workshops, and mango festivals in Pakistan. 


\section{References}

Aujla, K. M., Abbas, M., Mahmood, K., \& Saadullah, S. (2007). Marketing system of fruits, margins and export potential in Pakistan. Pakistan Journal of Social Sciences, 5(1-2), 34-39.

Charemza, W. C., \& Deadman, D. F. (1992). New directions in econometric practice: General to specific modeling, cointegration and vector autoregression. Aldershot, UK: Edward Elgar.

Cuthbertson, K., Hall, S. G., \& Taylor, M. P. (1992). Applied econometric techniques. New York, NY: Philip Allan.

Dickey, D. A., \& Fuller, W. A. (1981). Likelihood ratio statistics for autoregressive time series with a unit root. Econometrica, 49, 10571072.

Dolado, J., Jenkinson, T., \& Sosvilla-Rivero, S. S. (1991). Cointegration and unit roots. Journal of Economic Surveys, 4, 249-273.

Engle, R. F., \& Granger, C. W. J. (1987). Cointegration and error correction: Representation, estimation and testing. Econometrica, 55(2), 251-276.

Food and Agriculture Organization. (2007). FAOSTAT. Retrieved February 20, 2007, from http:/ / www.faostat.fao.org

Granger, C. W. J. (1981). Some properties of time series data and their use in econometric model specification. Journal of Econometrics, 16(1), 121-130.

Granger, C. W. J. (1983). Cointegrated variables and error correcting models (Discussion Paper 83-13). San Diego, CA: University of California, San Diego.

Granger, C. W. J., \& Newbold, P. (1974). Spurious regressions in econometrics. Journal of Econometrics, 2, 111-120.

Gujarati, D. N. (1995). Basic econometrics (3rd ed.). New York, NY: McGraw-Hill. 
Gunawardana, P. J., Kidane, H., \& Kulendran, N. (1995). Export supply response of the Australian citrus industry. Australian Journal of Agricultural Economics, 39(3), 247-261.

Haleem, U. (2005). Export supply response of citrus and mango from Pakistan. Unpublished master's thesis, University of Agriculture, Faisalabad, Pakistan, Department of Agricultural Economics.

Haleem, U., Mushtaq, K., Abbas, A., \& Sheikh, A. D. (2005). Estimation of export supply function for citrus fruit in Pakistan. Pakistan Development Review, 44(4, Pt. II), 659-672.

Harris, R. (1995). Using cointegration analysis in econometric modeling. New York, NY: Prentice Hall/Harvester Wheatsheaf.

Hassan, A. H., \& Ibnouf, M. A. (2005). Competitive capacity determinants for Egyptian exports of some fruits in the Saudi Arabian market. Agricultural Sciences, 32(2), 259-266.

Hendry, D. F., \& Ericsson, N. R. (1991). Modeling the demand for narrow money in the United Kingdom and the United States. European Economic Review, 35(4), 833-886.

Islam, N. (1990). Horticultural exports of developing countries: Past performance, future prospects and policy issues (Research Report No. 80). Washington, DC: International Food Policy Research Institute.

Johansen, S. (1988). Statistical analysis of cointegrating vectors. Journal of Economic Dynamics and Control, 12, 231-254.

Johansen, S., \& Juselius, K. (1990). Maximum likelihood estimation and inference on cointegration with applications to the demand for money. Oxford Bulletin of Economics and Statistics, 52(2), 169-210.

Neef, R. (2004). Export results for fresh fruits in 2003. Fruitteelt, 17(8), 1416.

Osterwald-Lenum, M. (1992). A note with fractiles of the asymptotic distribution of the maximum likelihood cointegrating rank test statistics: Four cases. Oxford Bulletin of Economics and Statistics, 54, 461-472. 
Pakistan Horticulture Development and Export Board. (2005). Mango marketing strategy. Islamabad, Pakistan: Ministry of Food, Agriculture and Livestock.

Pakistan Ministry of Finance. (2009). Pakistan economic survey 2008-09. Islamabad, Pakistan.

Pakistan Ministry of Food, Agriculture and Livestock. (2007). Fruit, vegetable and condiment statistics of Pakistan 2006-07. Islamabad, Pakistan.

Pakistan Ministry of Food, Agriculture and Livestock. (2008). Agricultural statistics of Pakistan 2007-08. Islamabad, Pakistan.

Reddy, V. R., \& Narayan, K. B. (1992). Trade experience of Indian agriculture: Behavior of net export supply functions for dominant commodities. Indian Journal of Agricultural Economics, 47(1), 48-61.

Tambi, N. E. (1999). Cointegration and error-correction modeling of agricultural export supply in Cameroon. Agricultural Economics, 20,57-67. 